colegiado, prescrito pelo artigo 217 da Constituição do Rio Grande do Sul, importa simplesmente em que o funcionamento dêsse "órgão se há de operar "a latere" da escala hierárquica, na qual deveria êle situar-se abaixo dos Secretários de Estado, equiparáveis aos Ministros, tradicionalmente em segundo lugar, após o Chefe de Estado (cf. Pereira do Rego, Elementos de Direito Administrativo Brasileiro, Recife, 1860, § 28, p. 20; Ribas, Direito Administrativo Brasileiro, Rio de Janeiro, 1866, p. 184; Alcides Cruz, Direito Administrativo Brasileiro, Rio de Janeiro, 1914, nr. 28, p. 60), situando-se, ao invés, em imediata subordinação à função do Governador do Estado.

b) As manifestações dêsse órgão, caracterizadamente consultivo, não poderão consistir senão em pareceres, com o conteúdo dos quais o Governador do Estado poderá conformar-se, ou não, a seu juízo, de vez que nem se acena, em texto algum, à eficácia vinculativa de tais manifestações, nem seria ela, de resto, admissível face ao princípio, inerente ao regime presidencial, impôsto aos Estados pela Constituição Federal (art. 7, VII, b; art. 36), segundo o qual, no caso, ao Governador do Estado cabe essencialmente todo o Poder Executivo (art. 76, Const. Est.; cf. Rui Barbosa, Comentários à Constituição Federal Brasileira, coligidos e ordenados por Homero Pires, t. III, São Paulo, 1933, p. 9; Pedro dos Santos, Os Nossos Ministros de Estado, Rio de Janeiro, 1934, passim). Ao demais, se a disposição da Constituição do Rio Grande do Sul pudesse admitir, nêsse particular dois entendimentos, opostos entre si, ainda assim, o que adotamos háveria que ser preferido.

$\mathrm{O}$ entendimento oposto acarretaria inevitàvelmente a inconstitucionalidade, por quebramento do princípio presidencialista, dessa disposição do Estatuto Riograndense, em contraste com o Estatuto Federal. A tál entendimento invalidatório não nos conduz, porém, a regra de exegese aplicável; bem ao contrário, a regra de exegese a ser obedecida é a de que, na hipótese, "aquela interpretação será adotada, que evite o efeito de inconstitucionalidade"; "if there is doubt or uncertainty as to the meaning of the legislature, if the words or provisions of the statute are obscure, or if the enactment is fairly susceptible of two or more constructions, that interpretation will de adopted which will avoid the effect of unconstitutionality" ( $\mathrm{H}$. Campbell Black, Handbook on the Construction and Interpretation of the Laws, St. Paul, Minn., 1896, nr. 43, p. 94; cf. Carlos Maximiliano, Hermenêutica e Aplicação do Direito, Pôrto Alegre, 1925, nr. 367, p. 314).

Êste é o nosso parecer, s. m. j.

\section{CENTENÁRIO DE RUY BARBOSA}

Além das comemorações efetuadas na Faculdade de Direito por ocasião da passagem do centenário do nascimento do excelso brasileiro, conforme foi registrado no primeiro número desta Revista, o Grêmio Universitário Tobias Barreto, entidade cultural dos acadêmicos de Direito, realizou também uma sessão em homenagem à memória de Ruy, tendo convidado o professor Edgar Luiz Schneider para falar na solenidade.

O “Grêmio Universitário Tobias Barreto" é uma associação exclusivamente de estudantes, autônoma na sua organização e na sua vida, e desde a sua fundação, em 1935 , vem prestando assinalados benefícios à mocidade estudiosa, com a realização de seus objetivos culturais.

Foi a seguinte a conferência pronunciada pelo prof. EDGAR LUIZ SCHNEIDER, sob o título

\section{"RUY E A MOCIDADE"}

"Entre as várias comemorações, que magnificam o centenário de Ruy Barbosa, maior e mais expressiva será, sem dúvida, a comemoração promovida pela mocidade.

\section{A' FEIÇÃO DE PERICLES}

Foi ela que o genial brasileiro, à semelhança de Péricles, sempre exaltou e, poristo mesmo, deverá recolher e seguir suas lições que contêm um sentido profético, nesta luta mundial pela democracia, ęm cuja predicação foi constante e insuperável.

As convicções que exprimiu e os foros que sustentou, passado um quarto-de-século, transfundem hoje a plenitude de suas fontes, onde se espelha um idealismo sereno e sem jaça.

Estêve nisso, por certo, a eminência solar do político, que soube antever e a viva transcendência do apóstolo, que soube sentir abrindo um caminho a seu próprio destino, sobranceiro a todos os desenganos em meio aos quais nunca esmoreceu e jamais recuou. 
Nessa individualidade que fulgiu, ao longo de dois regimes, dando de si, em cruzadas memoráveis, a exuberância e o fragor do verbo, que nenhum outro excedeu, ao mesmo tempo que difundia os primores da cultura e da beleza, assoma e esplende uma grandeza diáfana e rediviva.

Assim o contemplou a Nação, nos áureos dias, que foram os seus, defensor ardente da abolição, ou intransigente paladino do direito, sempre ao serviço de tôdas as reivindicações justas, entre as quais se robusteceram e sublimaram as energias do batalhdor indefesso e generoso.

Desaparecido embora do cenário, que encheu de vibração e de fulgor, eis que continua a ressurgir, anos em fora, como um símbolo às gerações, que se sucedam.

$\mathrm{E}^{\prime}$ o que mostra, neste instante, a juventude estudiosa, que traz a sua reverência, sem artifícios, ao maior e mais desvelado entre os mestres, assim pelo que fêz como pelo que disse, devotado sempre ao engrandecimento e à dignificação da Pátria.

Sobra a evidência da intenção, que assiste aos nobres mancebos, nesse culto venerável, pois seus ainda são os problemas nos quais Ruy Barbosa afundava o espírito e concentrava o fervor dos grandes prélios em busca da solução às graves crises nacionais.

Evocar a eloqüência, que deslumbrava e as exortações, que persuadiam, é reviver as campanhas liberais de maior ressonância nas crônicas do civismo brasileiro.

Ainda que mudados os tempos e outras as geraç̃es, não variou a substância das reivindicações humanas, que subsistem e se alongam numa inquietação cada vez mais sensível e profurida.

Não foi sem razão que o insigne homem público, em plena ascensão, advertia que aos moços, dignos dêste apanágio, que também o teve, em espírito, até aos derradeiros instantes, não podiam e não deviam senão pugnar pela verdade, pela liberdade e pela humanidade.

\section{GERAĞÃO INQUIETA}

Tríplice consórcio, que exprime e resume, numa síntese magistral, as questões que trabalham a consciência e galvanizam as forç̧as da criatura, ciosa do direito de viver, sem constrangimento e sem mistificações.

Ontem como hoje, são os anseios que ainda não atingiram, nas conquistas que se encadeiam, o ponto alto da jornada, que será a definitiva redenção da espécie, entregue à fruição e ao comando da própria vida, mediante a expansão tranqüila e segura de suas aptidóes e de suas energias.

Geração que nasceu entre duas guerras, explica-se que seja, também, a menos contente e a mais alvoroçada, diante do mundo revôlto e à procura de apoio, em meio da confusão e perplexidade reinantes.
Por certo, vastas e sensíveis têm sido, através do orbe habitado, as transformações que, a partir da primeira conflagração européia sofreram as franquias e os valores da civilizaçấo. O que hoje preocupa, nas porfias cotidianas, é a sobrevivência do homem, sem usurpações e sem temores, por meio da eqüivalência nos direitos e nas oportunidades. Já não basta a igualdade, senão que importa assegurar a todos os sêres, que integram a comunhâo social, um ensêjo irrestrito ao trabalho e ao bem-estar.

Sob tais influxos, desenvolvidos ao arrepio da guerra, surgiram e consubstanciaram-se, em estatuto explícito, os direitos e deveres internacionais do homem, que sobrepaira às fronteiras políticas e aos prejuízos raciais.

Não foi doutra natureza, entre nós, a orientação que cedo contraiu Ruy Barbosa, propugnando a recondução do escravo ao plano humano e fazendo-o titular de iguais direitos, entre os quais estaria o da livre escolha do trabalho e o gôzo tranqüilo de seus frutos.

Mais alto remontou, nas esferas internacionais, onde preconizou e defendeu a igualdade jurídica dos Estados soberanos, que os arautos do imperialismo geográfico e político se recusavam em admitir, receosos de encurtar as perpectivas à exploração econômica das populações inermes.

\section{SÁBIO E PROFETA}

A sua atitude em Haia, que o sagrou entre seus sábios, consistiu em evidenciar a necessidade do arbitramento obrigatório, em cuja adoção já o Brasil se havia antecipado aos demais países.

Quando tanto se fala, hoje, em manutenção da paz e segurança entre os povos, fôra de rigor que, entre seus paladinos, se concedesse um lugar saliente ao homem que só não consentiu fôsse objetivada pela neutralidade entre o direito e o crime, como o demonstrou através do monumental discurso da Faculdade de Direito de Buenos Aires.

São gestos e palavras nos quais o inolvidável brasileiro enunciou, sem variação e sem pausa, a profunda convicção que, assim procedendo, difundia e prestigiava, ao lado de tantos outros, o evangelho da humanidade, entendido como a súmula de todos os direitos essenciais.

Quis sempre que, assim os povos como as criaturas, não hesitassem em fazer praça da fraternidade e resolver, sob os auspícios da cooperação e da harmonia, as suas contendas, uma vez que não existem prevenções irredutíveis.

Bem sentia que não se pudera, fora dêsse ambiente, dar aos direitos humanos um sentido universal, que garantisse deveras ao homem, em todos os meridianos e debaixo de qualquer bandeira, uma existência sem restrições nem atropelos.

Nessa batalha que encetou e prosseguiu, anos sem conta, personificou a intuição das grandes reivindicações sociais, pois foi sobretudo 
a segunda conflagração que as definiu e vulcanizou, ao mesmo tempo que as trouxe em equação decisiva às varias nações e seus dirigentes, tendo de permeio a "cortina de aço", que divide o mundo em dois continentes antagônicos, um dos quais e felizmente o maior conserva os moldes democráticos.

Mas, ao passo que ao gênero humano não denegou um só de seus direitos, é certo que teve, invariàvelmente, entre os mais altos, a liberdade em seus múltiplos e variados aspectos.

Sem ela não há direito, que perdure e à sombra dela tôdas as conquistas germinam e se desatam em benefícios, que são outros tantos estímulos ao progresso e bem-estar gerais.

Disse-o Ruy Barbosa que "só onde a unidade humana fôr livre, a coletividade humana pode ser consciente", e, nesta assercão, que arranca da observação corrente e mais da contínua experiência histórica, avulta a própria altitude da liberdade, como condição inseparável da evolução social entre os povos desejosos de subsistir, de prosperar de engrandecer-se.

\section{ORATÓRIA SEM JAĢA}

Foram igualmente suas, entre nós, as páginas mais vividas, que já se escreveram, em linguagem humana, sôbre a liberdade, como aspiração, como realidade, como direito.

Encarnou-a êle em Tiradentes, que assoma entre os batalhadores mais audazes e cuja memória arvorou em "padroeira nacional do direito", tanto se extremara o mártir divinizado em fazer da república, em pleno tumulto colonial, a duradoura encarnação do idealismo nascente.

Se evangelho houvera a liberdade de possuir, em nosso país, como expressão de suas promessas e afirmação de suas conquistas, maior não o teria que nessa peroração lapidar de Ruy Barbosa, onde não se sabe que mais exaltar, se as peregrinas gemas do artífice, ou o sentido divinatório de suas reflexões, que abrem uma alvorada de esperanças entre as dúvidas mais atrozes.

Jamais a oratória subiu tanto e nunca a evidência foi mais completa, nas palavras e nó fatos, pois o fulgor da forma se associou a dialética, que desofusca e que convence.

Entretanto, não basta ser humano e ser livre, senão que cabe, em ambos os sentimentos, ter a verdade como pedestal, e, nesta condição, tanto que outra não a substitui, há-de assentar o roteiro, que dignifica e que liberta.

Daí asseverar Ruy Barbosa que "a paixão da verdade semelha, por vêzes, às cachoeiras da serra", e, nesta imagem alpina, que espelha e remonta as maravilhas da fôrça em expansão, eis que se surpreende o valor da certeza, da confiança e da justiça, como os requisitos sem os quais não há paz, que se afirme e não há convivência, que persista.
Ser verdadeiro é, portanto, um dever que se impõe à juventude, que cuida manter, sobranceiros e intangíveis, os seus ideais, sem transigir com a simulação, com o arbítrio e com a usurpação.

E' sobretudo a luta contra a violência, a fraude e a mentira, que aliciam e perjuram, que conspiram e arremetem, que solapam e destróem.

Outro atributo não houve que Ruy Barbosa tanto enaltecesse e dêle fizesse mais alta entre as virtudes do advogado, que a própria verdade, como perene luzeiro nos seus embates e esteio vivo de suas vitórias.

Suas batalhas mais árduas gravitaram em tôrno da verdade cons, titucional, da verdade republicana e da verdade democrática, que o tiveram, sem desmaios, à frente dos lidadores intrépidos e desassombrados.

Nesse espírito se embeberam os múltiplos e variados trabalhos do ofício, pois que o exerceu, com a seriedade do apóstolo, a proficiência do mestre e a erudição do sábio, sem nunca desgarrar do caminho da justiça, que seguiu tranqüilo e seguro, para colhêr, ao têrmo dêle, a consagração e os aplausos mesmo entre os adversários.

\section{ADVOGADO E JURISTA}

Em meio-século de atividade profissional, tendo em mãos as lides mais memoráveis, foi pródigo em arrasoados e pareceres, nos quais soube primar pela profundeza nos argumentos e pela translucidez da forma, enriquecendo as letras jurídicas do país, através de monografias que, ainda hoje, se reputam modelares.

Poder-se-ia assegurar que seus ensaios, onde tanto há-que admirar e rever, são lições que se perpetuam, granjeando ao mestre sem cátedra universitária a notoriedade, que singulariza e que glorifica.

Maiores não podiam ser, pois, os móveis inspiradores dos estudantes de direito, que trazem ao convívio desta hora, numa comemoração festiva, a figura sem par de Ruy Barbosa.

Dêsse que, sumidade entre as mais altas e despida inteira de vaidade, não se teve que não dissesse de si, em confissão que tanto ensina quanto edifica: "Estudante sou. Nada mais. Mau sabedor, fraco jurista, mesquinho advogado, pouco mais sei do que saber estudar, saber como se estuda, e saber que tenho estudado".

Porque soube estudar, eis que acumulou, amadureceu e difundiu, entre seus semelhantes, as sementes de oiro, que são suas lições e suas obras, nas quais se descobre um cabedal de perdulário, desadvertido da riqueza, que possuía e absorvido pelas maravilhas, que o singularizavam. 
Assim o foi e aflora assim à evocação, nos dias que correm, porque sempre entendeu que à Patria se serve, menos pela exaltar nas sua belezas e a contemplar nos seus prodígios, que a engrandecendo e a ilustrando pelo ideal e pelo trabalho.

\section{O SOLDADO DO IDEAL}

Seu foi o ideal, que brotou de nascentes sem jaça e permaneceu entre as linfas mais puras, acordando o entusiasmo e movendo à pertinácia excelsa e valorosa, em cujo âmbito se caldeiam a ascensão e a glória. Ninguém ainda mais prezou o seu que o gênio baiano, fiel e devotado às suas promessas, que realizou ao longo duma existência enobrecida e agigantada.

"Os frutos da minha vida, afirmou-o certa vez entre desenganado e humilde, são escassos e tristes, bem que seus ideais tenham sido grandes e belos".

Belos e grandes foram, sem dúvida, suas orações e seus escritos, que constituem um repositório inconfundível, onde sobreexcele a cultura e o engenho, nas obras mais primas e nos préstimos menos contingentes.

Mas, releva não esquecer que, a par com a inteligência de escol, teve a concorrer para tais resultados uma faina sem tréguas, que alvorescia com as madrugadas, "incessante e persistente como o sol de todos os dias e o orvalho de tôdas as noites".

Um labor que se embebeu do ideal e se desdobrou, com firmeza e sem amargor, que lhe entrou vida adentro, empolgando espírito e coração, nas suas efusões e nas suas crenças.

Não foi outro o trabalho, como o êle amou, como o êle sentiu, "como é mister, para regenerar o homem, para transformar os povos, para criar os moços".

Dêsse modo soube honrar e servir a Pátria, que deveras o estremeceu e ainda o tem, nesta altura inquieta de seus destinos, à feição de oráculo, cuja palavra os sãos procuram escutar e os dignos buscam seguir.

Aonde quer que o arrastaram os imperativos da vocação, ou as variações do ofício - a tribuna, o parlamento, a imprensa, as letras, pontificou e cresceu, aurejou e persuadiu, ascendeu e fascinou.

Tomado a peito um litígio e iniciada uma campanha, não havia ameaça que o amedrontasse, perigo que o detivesse, hesitação que o vencesse.

Assim se explica porque suscitou desafetos e atraiu inimigos um homem que, alvo da rivalidade e da inveja, nada fêz pelo agradar senão tudo pelo resistir ao capricho e à truculência dos potentados do dia.
Muito teve, pois, em tôrno de si, que escoriar, que debater e que convelir, abrigando os bons e acometendo os maus, numa campanha aberta e sem descanso pela Nação e pela República, nos seus fundamentos e nas suas esperanças, trazendo ambas ao largo estuário da democracia vigilante e redentora.

Diante dessa obra portentosa, que havia de ultrapassar, em muito, as previsões comuns, quase se dissera, sem exagêro algum, vertendo as palavras do varão imortal, que estão redivivos seus rebates de atalaia, suas vozes de guerreador, seus vaticínios de profeta.

E' o que incumbe, neste momento, à mocidade estudiosa ouvir e acolher, tendo presente ao espírito que, segundo Ruy Barbosa, "os que servem a Pátria são os que não invejam, os que não infamam, os que não conspiram, os que não sublevam, os que não desalentam, os que não emudecem, os que não se acobardam, mas resistem, mas ensinam, mas esforçam, mas pacificam, mas discutern, mas praticam a justiça, a admiração e o entusiasmo",

\section{Congresso de Direito Constitucional da Bahia}

Constituiu um êxito extraordinário a realização, na capital baiana, do Congresso de Direito Constitucional, de 5 a 11 de novembro de 1949, comemorativo do centenário do nascimento de Ruy Barbosa.

Estiveram presentes àquele certame juristas de quase todos os Estados da Federaç̃o (apenas quatro não se fazendo representar), não tendo faltado sequer a presença do sr. ministro Laudo de Camargo, presidente do Supremo Tribunal Federal.

A presidência efetiva do Congresso coube ao dr. Jayme Baleeiro, presidente do Instituto da Ordem dos Advogados da Bahia, instituição que animou e efetivou a notável reunião, tendo as sessões solenes, realizadas no "Forum Ruy Barbosa", sido presididas pelo governador Octávio Mangabeira.

Foi alto o número de trabalhos apresentados e do melhor quilate a sua matéria, subscritos por alguns dos mais altos nomes do jurismo nacional.

O estudo "Presidencialismo e Parlamentarismo na ideologia de Rui Barbosa", da autoria do dr. Paulo Brossard de Souza Pinto, publicado no primeiro número desta "Revista", teve como relator o prof. Edgardo de Castro Rebelo, da Universidade do Brasil, e foi unanimemente aprovado.

A tese intitulada "Em tôrno da emenda parlamentarista", do mesmo autor, que a defendeu como representante do Instituto da Ordem dos Advogados do Rio Grande do Sul, foi relatada pelo prof. A. de Sampaio Doria, cujas conclusões foram combatidas pelo professor da Faculdade de S. Paulo, mas a comissão primeiro, e depois o plenário, aceitaram por significativa maioria.

Os organizadores do Congresso de Direito Constitucional, juntamente com o Instituto da Ordem dos Advogados da Bahia, publicarão os seus "Anais", que revelarão a valia das teses apresentadas e a altissima homenagem que constituiu à memória do constitucionalista sem par e jurisconsulto insígne que foi Ruy Barbosa. 